\title{
Modelos de apego, homossexualidade masculina, e depressão: um relato de experiência
}

\author{
Dilcio Dantas Guedes \\ Universidade Estadual do Piauí \\ Julieta Monteiro-Leitner \\ Southeast Missouri State University
}

\begin{abstract}
Resumo
Relatam-se casos clínicos de dois rapazes, que buscaram psicoterapia a partir de demandas afetivas e amorosas. Enfatizam-se a análise de seus modelos de apego e a queixa de depressão em relação a suas experiências homoafetivas. Partiu-se das suposições de que: (1) os modelos comportamentais de apego com os pais repetirse-iam com os parceiros; e (2) o nível de segurança das relações amorosas mediaria inversamente o nível da depressão. Articularam-se dados da mensuração dos níveis de depressão pelo Inventário de Depressão Beck (BDI) e da Attachment Security and Secondary Strategies Interview (ASSSI). Os resultados indicaram que os modelos de apego aos pais parecem ter influenciado as representações de apego e experiências amorosas, que pareceram mediar os níveis da depressão.
\end{abstract}

Palavras-chave: apego; separação; relações amorosas; depressão; homossexualidade

\begin{abstract}
Models of attachment, homosexuality and depression: an intervention report. Case studies of two young men are reported. Their reason for seeking psychotherapy lies in their affection and romantic love problems, what led us to an effort to understand their models of attachment and depression complaints in regard to their homoaffective experiences. Authors assumed that: (1) attachment models experienced with their parents would be repeated with love partners, and (2) the level of steadiness in the romantic relationship would inversely mediate the level of depression. Depression data obtained by means of Beck Depression Inventory (BDI) were related to equivalent information generated by Attachment Security and Secondary Strategies Interview (ASSSI). Results showed that models of attachment to the parents seemed to have influenced the attachment representations' and love relationships, which seemed to have mediated the levels of depression.
\end{abstract}

Keywords: attachment; breakups; love relationships, depression; homosexuality

$\mathrm{V}$ erifica-se uma crescente busca de suporte psicoterápico em decorrência das vivências afetivo-amorosas, que evidenciam experiências marcadas pela dificuldade em formar, manter e, sobretudo, em enfrentar situações de ruptura. A partir da leitura da dinâmica do sistema de apego, procurouse compreender a vivência das relações amorosas e seus desdobramentos em dois casos clínicos, cujo modelo amoroso era homoafetivo e cujas demandas estavam em torno das dificuldades do relacionamento e de sinais clínicos de depressão.

\section{Aspectos teóricos da dinâmica do apego e as relações homoeróticas}

Parte-se da concepção de comportamentos de apego, proposta por Bowlby $(1969,1973,1980)$. Tais comportamentos compõem um sistema motivacional, objetivando a manutenção da proximidade e do apoio de figuras de apego. Estas promovem e mantêm uma base de segurança e de "porto seguro" em qualquer situação ameaçadora para o indivíduo. A experiência dessa "base" favorecida (ou não) pelas figuras de apego constituirá, a partir do período das representações simbólicas, a estrutura de conhecimento sobre os sinais emitidos pelas pessoas que indicam possibilidade ou impossibilidade de formar ou manter o apego. Essa assimilação acionaria ou inibiria a apresentação de comportamentos a fim de manter a homeostase do sistema relacional entre o indivíduo e sua(s) figura(s) de apego. A princípio, essas figuras são os pais ou seus substitutos; na adolescência e nas fases posteriores, os amigos e parceiros amorosos podem vir a representar figuras primárias de apego na ausência definitiva dos pais ou substitutos.

A compreensão dessa dinâmica permitiu que Ainsworth (1978) e Main (1990) propusessem categorias de tipos de apego segundo o modelo internalizado que os indivíduos constroem a partir das experiências na relação com suas figuras de apego (parentais ou não). 
O estilo seguro de apego caracterizaria os indivíduos que procuram reconforto e apoio das figuras de apego quando se encontram em situação de estresse (i.e., separação, ou outra fonte de ameaça real da ruptura do laço), mas que retornam ao estado de tranqüilidade (homeostase) quando a figura de apego apresenta-se e fornece apoio, possibilitando retornar a atenção para outros domínios de interesse.

$\mathrm{O}$ estilo ansioso-resistente caracterizaria os indivíduos que procuram reconforto e apoio das figuras de apego de forma compulsiva sem que, necessariamente, encontre-se em situação de estresse. Ainda assim, eles não retornam ao estado de tranqüilidade quando a figura de apego apresenta-se e fornece apoio. Pessoas com este estilo demonstram insatisfação e resistência ao receber apoio e permanecem ansiosos quanto à possibilidade de uma nova separação - o que as impede de voltar sua atenção para outros domínios de sua vida.

$\mathrm{O}$ estilo evitante caracterizaria os indivíduos que inibem comportamentos de procura do reconforto e do apoio das figuras de apego quando se encontram em situação de estresse, a fim de evitarem o afastamento dessas figuras ou os laços de dependência. Nesse sentido, procuram focalizar sua atenção em outros domínios externos, que não os do apego (Hazan \& Shaver, 1987).

E, finalmente, o estilo desorganizado não sabe qual recurso empregar para retornar ao estado de homeostase; seja porque as respostas da figura de apego expressam fragilidade (teme ser a causa da falência dessa personagem), seja por que as respostas da figura de apego geram temor. Por exemplo, as pessoas ligadas a figuras parentais que sofrem de grave depressão, ou de algum transtorno grave pós-traumático, ou ligadas a figuras agressivas, temem sofrer com as ações dessa figura de apego e, ao mesmo tempo, sobrecarregá-las com demandas de apego.

Hazan, Zeifman e Middleton (1994) afirmam que não existem diferenças entre os comportamentos de ativação ou inibição do sistema de apego entre indivíduos vivendo relações com pessoas do mesmo sexo e indivíduos heterossexuais. Por sua vez, Mohr (1999) aponta que, possivelmente, se o indivíduo que vive um relacionamento com uma pessoa do mesmo sexo possui um estilo seguro, este procuraria ampliar seus espaços de vivência, pois reconheceria os perigos que poderia sofrer em ambientes hostis. Estes também teriam maior habilidade para desenvolverem comportamentos defensivos mais eficazes no enfrentamento de atos de intolerância para com sua orientação sexual, reforçando, assim, sua identidade sexual (Mohr \& Fassinger, 2006).

No entanto, os indivíduos inseguros extrapolariam sua insegurança do apego para a sua própria sexualidade e, por conseqüência, para suas relações pessoais. Para estes, as representações homofóbicas seriam fortemente internalizadas (sobretudo para os indivíduos evitativos) e a vivência afetiva teria uma tendência para conflitos permanentes, seja pela necessidade de haver expressão freqüente da manutenção do laço (como para os ansiosos-resistentes), seja pela necessidade em manter a relação afetiva pouco comprometida e "escondida" (como para os evitativos).

Em termos da dinâmica das relações amorosas, dois pontos são cruciais para a formação: primeiro, é a busca de uma segurança emocional mútua e, segundo, a atração sexual como um importante componente para a formação de um laço de intimidade. No entanto, estes dois aspectos não são exclusivos.

Hazan \& Zeifman (1999) propõem que, para haver a formação do apego entre adultos, é preciso que haja uma fase de pré-apego, na qual exista a atração sexual; uma fase da paixão em que os futuros parceiros procurem ampliar seu conhecimento mútuo, confirmando ou não que poderá haver um laço que promova suporte emocional para, a partir daí, haver um apego formado. A fase seguinte seria uma estabilização da relação que, se for segura, permitirá um investimento emocional em outros domínios da vida social. Assim, a dinâmica de ativação e desativação do sistema de apego manteria o fluxo da relação amorosa. Se a relação for insegura, essa ativação tende a ser inibida (procura prescindir do parceiro) ou hiperativada (procura exageradamente manter o parceiro próximo e vigilante às demandas expressas) (Guedes \& Miljkovitch, 2005).

\section{Elementos teóricos sobre a depressão}

Os parâmetros teóricos acerca da depressão foram articulados a partir dos critérios do DSM-IV (American Psychiatric Association, 2000). A depressão é caracteristicamente definida pelo humor deprimido, concentração e atenção reduzidas, redução da autoconfiança; idéias de culpa e inutilidade, visões desoladas e pessimistas do futuro, idéias ou atos auto lesivos ou de suicídio, sono perturbado, inapetência, ganho ou perda de peso e irritabilidade.

Os episódios depressivos se diferenciam da depressão categoricamente clínica: a duração de duas semanas é usualmente requerida para o diagnóstico da depressão clínica (American Psychiatric Association, 2000). Do ponto de vista psicoterápico, salienta-se a diferença da etiologia da depressão entre uma pessoa constitucionalmente depressiva e aquela que se deprimiu como uma resposta ao insucesso da relação amorosa. Nos casos relatados a seguir, o fator ambiental (separação) e afetivo são considerados como importantes estressores desencadeadores do episódio, já que os indivíduos não possuíam sinais do transtorno anteriormente às rupturas amorosas.

A partir dessas considerações, suspeitamos que exista uma relação entre o modelo comportamental de apego e a vivência da depressão experienciada pelos clientes que participaram do estudo, a saber: (1) os modelos comportamentais de apego com os pais parecem repetir-se com os parceiros amorosos; e (2) o nível de segurança das relações amorosas parece mediar inversamente o nível da depressão dos indivíduos envolvidos (quando o nível da segurança e de ativação do sistema de apego cai, o da depressão aumenta).

\section{Método}

Trata-se de um estudo de dois casos atendidos em psicoterapia. Os participantes foram dois adultos jovens com orientação sexual homoafetiva, cujas idades eram 26 e 22 anos, e que buscaram a psicoterapia com demandas relacionadas a 
depressão e vivências amorosas. Este estudo focalizou os dados dos níveis de depressão, segundo o Inventário Beck de Depressão (Beck Depression Inventory, BDI) e as representações de apego vivido com os pais e parceiros amorosos segundo a Attachment Security and Secondary Strategies Interview (ASSSI), uma entrevista sobre segurança e ativação do sistema de apego nas relações de apego (Miljkovitch, 2005).

O Inventário Beck de Depressão é composto por 21 grupos de quatro afirmações que descrevem a forma como a pessoa tem se sentido durante um período determinado do mês. Os participantes poderiam receber um valor máximo variando de 0 a 63 pontos. Quanto maior o escore, maior o nível da depressão. A escala foi aplicada em diferentes momentos do processo psicoterápico dos participantes.

A entrevista sobre apego cobre as dimensões do sentimento de segurança e as reações de ativação do sistema de apego. Essas dimensões são avaliadas em torno das experiências de apego com os pais e com diferentes parceiros amorosos. As questões organizam-se em relação a circunstâncias de adoecimento, perigo, brigas e disponibilidades cotidianas com as figuras de apego. Ela permite evocar a dinâmica familiar e as situações de ruptura dos laços afetivos.

Cada participante recebe um escore para o sentimento de segurança e para reações de ativação representados. Uma cotação para segurança é utilizada e varia de zero a oito. O escore zero descreve uma segurança ausente, definida pelo sentimento total de rejeição ou de não-aceitação pela figura de apego, mesmo se os cuidados de base são assegurados. Inversamente, o escore oito descreve um segurança total, representando que o participante reconhece as respostas de apego como adaptadas às suas necessidades, sentindo-se satisfeito e livre para expressar seus afetos ou opiniões. Igualmente, uma cotação para reações de ativação do sistema de apego é utilizada, variando de -8 a +8 . Os pontos negativos correspondem às reações de inibição, e os positivos às reações de hiper-ativação do sistema de apego. $\mathrm{O}$ escore zero indica uma ativação ótima; menos oito corresponde a uma inibição extrema (o sujeito se afasta totalmente da relação com suas figuras de apego, evitando proximidade afetiva e física, enfrentando seus problemas sozinho); enquanto que mais oito corresponde a uma hiper-ativação extrema, na qual o indivíduo desenvolve comportamentos exagerados de manutenção da relação de apego, sendo extremamente dependente, mesmo sem ameaça de rompimento do laço afetivo. As respostas da ASSSI foram obtidas pelos dados clínicos colhidos no decorrer do processo e complementadas em entrevistas que compuseram as sessões de avaliação, assim como em relação às respostas do inventário de depressão.

\section{Resultados}

\section{Descrição do caso A}

Para fins deste relato, chamaremos o participante de Caio. Ele é o irmão mais velho de dois outros. Seus pais separaramse quando tinha oito anos de idade. Desde então, mora com a mãe e irmãos. Segundo suas descrições, a mãe apresenta um modelo autoritário de educação. É “explosiva” (sic) e se utiliza de "humilhações públicas" ao exercer sua autoridade. O pai é visto como "brincalhão e inconseqüente" (sic) e, geralmente, cria conflitos no momento de assumir responsabilidades financeiras para com os filhos. Sua vida escolar transcorreu sem acompanhamento regular e sem elogios da parte dos pais. Não tinha apoio e atenção, e era punido (física e moralmente) quando não alçava êxito. Assim, optou pela auto-suficiência - mantendo bom desempenho, algumas vezes diminuído por "dispersão da concentração".

Durante a terceira infância estabelecia brincadeiras sexuais com um vizinho, até que foi surpreendido pela mãe, gerando grave conflito familiar. Com 12 anos teve sua primeira relação sexual com um homem, "em uma situação de risco de exposição [ser visto por alguém]". Caio manteve namoros com meninas, mas o rapport sexual com garotos manteve-se "de forma clandestina". No período da vida em que freqüentou a universidade, conheceu um rapaz nove anos mais velho, com o qual se relacionou durante três anos.

Nesse período, Caio asseverou a continuação de atos sexuais com risco de exposição e também sem uso de preservativos; considerando-os satisfatórios, pois, segundo seus relatos, o parceiro era "paternal". Até o momento em que conflitos decorrentes de dúvidas de traições e de controle de conflitos acabaram engendrando possibilidades de ruptura (por exemplo, Caio tendia a assumir uma posição dominadora e intransigente). Meses depois, conheceu outro homem, igualmente mais velho, e decidiu romper a antiga relação. Esse rompimento deu-se de forma não-amigável. O novo relacionamento começou a se desenvolver. Seu atual companheiro é, conforme descreve, "paternal". No entanto, Caio cita o conflito permanente pela dúvida da fidelidade, em decorrência de experiências de "relações de risco" a doenças sexualmente transmissíveis vividas com o novo parceiro.

\section{Descrição do caso B}

Para fins deste relato, chamaremos o participante de Eduardo. É o filho mais velho de um grupo de mais dois irmãos. Seus pais permaneceram casados até ele completar dezoito anos, quando seu pai faleceu. Na infância morou na casa da avó paterna, recebendo visitas dos pais no final de semana. Segundo seus relatos, sua permanência na casa dos avós foi motivada para facilitar os cuidados maternos despendidos ao irmão mais novo recém-nascido. Depois de alguns anos, voltou para a casa dos pais, mas sua relação não é filial para com eles. O pai exercia um modelo autoritário, mas a mãe sempre intervia "em segredo" (sic), tentando contornar as intransigências paternas. Muito embora o falecimento do pai não tenha lhe causado forte impacto (devido à distância afetiva, como afirma em seu relato), acabou gerando, em sua mãe, expectativas de substituição desse papel (por exemplo, a guarda dos bens da casa, a responsabilidade pela educação moral da irmã, controle de gastos, etc.) - o que acarretou conflitos familiares.

Sua adolescência foi reservada, somente ampliando seu círculo de amizade durante o período que freqüentou a universidade. Nesse ínterim, Eduardo expôs sua orientação sexual 
para a mãe, mas isso não gerou diferença no plano familiar, pois, "era como se ela não soubesse". Na fase adulta, conheceu um rapaz da mesma idade e passou a ter um relacionamento com ele. No entanto, o parceiro era muito ocupado no trabalho e o deixava à margem. Assim permaneceu, até que decidiu romper essa relação.

Tempos depois, conheceu outro rapaz no trabalho. Mantiveram uma relação durante alguns meses, mas a inconstância do comportamento do parceiro e as crises de ciúmes acabaram por facilitar o rompimento. Finalmente, passou a conhecer pessoas através de chats na internet. Por estes encontros, conheceu seu terceiro parceiro. Tinham a mesma idade e tiveram alguns meses de "intensa paixão e cumplicidade". Porém, essa relação foi desequilibrada quando, o parceiro decidiu rompê-la, alegando o "constante estado depressivo" de Eduardo. Seu estado psicológico foi abalado e sua depressão retornou aos níveis elevados.

\section{Descrição dos dados quantitativos dos casos}

Nesta seção apresentam-se os resultados obtidos nas avaliações do BDI e na entrevista sobre apego (ASSSI).

Como se pode observar na Figura 1, a variação do BDI para Caio (caso A) evidencia uma progressiva queda dos índices de depressão no decorrer das avaliações, sendo 48 pontos na primeira, 47 na segunda, 44 na terceira, 28 na quarta, 13 pontos na quinta avaliação, mantendo nove pontos na fase de followup. Porém, para o caso B (Eduardo), existe uma flutuação mais variável e diretamente ligada às suas experiências de apego romântico. Do máximo de 63 pontos, ele obtém 50 pontos na primeira, 51 na segunda; 43 na terceira, 38 na quarta, 17 pontos na quinta avaliação, demonstrando uma queda acentuada de valores no momento que coincide com seu segundo namoro; e sobe para 47 pontos, com o desenlace dessa relação, para cair para 39 na última avaliação, o que é considerado um valor elevado para os parâmetros do BDI.

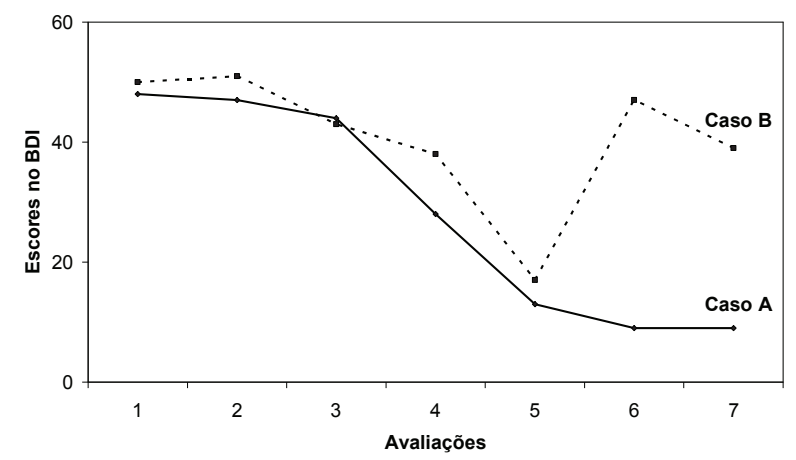

Figura 1. Escores obtidos no BDI durante o processo psicoterápico e follow-up.

A variação dos escores de segurança do apego (Figura 2) permite uma análise retrospectiva de todas as relações de apego e sua base de segurança. Segundo os dados representados, encontra-se que, para Caio (caso A), a cotação da representação de segurança foi baixa, caracteristicamente ausente para com o pai e para com a mãe (zero). A representação de segurança foi mais elevada para com os parceiros: fraca, para o primeiro $($ escore $=2)$; e relativa para o segundo parceiro (4). Para Eduardo (caso B), ela também resultou ausente (zero) para o pai e fraca (2) para a mãe. Igualmente ao caso A, as relações amorosas para Eduardo foram representadas como mais elevadas que em relação às cotações para o pai e a mãe: fraca (3) para o primeiro parceiro; e moderada para o segundo (6).

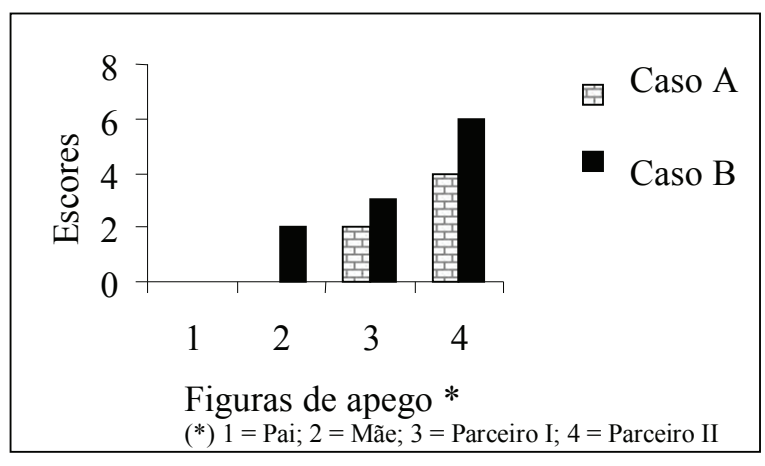

Figura 2. Escores de segurança de apego dos dois casos.

Quanto aos escores de ativação do sistema de apego, a Figura 3 exibe sua variação, permitindo uma retrospectiva representativa de todas as relações de apego e de sua ativação dos comportamentos aprendidos para manter o laço de apego e da base de segurança.

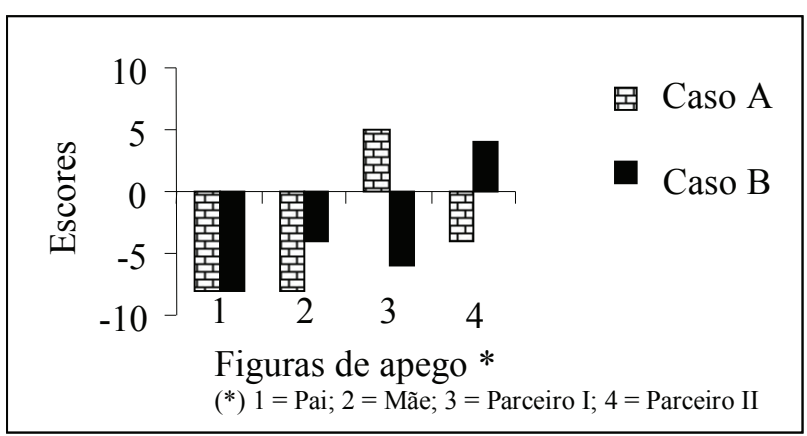

Figura 3. Escores de ativação do sistema de apego dos dois casos

Segundo os dados representados, encontra-se que para Caio, a representação da ativação do apego foi baixa, caracteristicamente ausente para com o pai e para com a mãe (-8), mas um pouco mais elevada para com os parceiros: hiperativada moderadamente (5) para o primeiro parceiro e inibida em níveis de moderada desativação do sistema de apego para o segundo (-4). Para Eduardo, ela também foi cotada como ausente para com o pai (-8), mas relativamente ativada para com a mãe (-4). Quanto às relações amorosas, percebeu-se uma ativação do sistema de apego em nível de forte inibição (-6) para o primeiro e uma hiper-ativação em termos relativos para o segundo parceiro (4). 


\section{Discussão}

\section{Caso A}

Os dados quantitativos mostram gradativa queda dos índices de depressão. Acredita-se que a psicoterapia tenha propiciado um conjunto de mudanças emocionais, além da diminuição dos sintomas depressivos. Entende-se que houve progressiva compreensão dos padrões de seus relacionamentos afetivoamorosos e a integração de representações sobre a formação e manutenção do apego nessas relações.

Caio relatava vivenciar um sentimento de menos valia, comprometimento intelectual e sexual e insegurança afetiva. Apresentava comportamentos de apego evitativos (por exemplo, comportamentos sexuais promíscuos recorrentes, desmotivação para formação de laços amorosos estáveis) de acordo com a definição de Hazan e Shaver (1987). No entanto, quando se ligou aos parceiros, passou a manifestar comportamentos ambivalentes e ansiosos, como medo de perdas, raiva de si por se perceber amorosamente dependente do ex-parceiro, articulado à carência afetiva de base e busca de substitutos em outras relações amorosas.

Acredita-se que tais comportamentos tenham decorrido da relação pouco segura com suas figuras de apego primárias e secundárias. Por exemplo, o estilo autoritário da mãe teria contribuído para a construção de representações pouco valorativas de si, assim como a posição passiva do pai teria incrementado sua representação de figura "não adulta" (sic). Tais aspectos pareceram engendrar sentimento de solidão ante o enfrentamento das dificuldades, muito embora os cuidados de base (em sua maioria instrumentais) fossem garantidos. Essa inconstância da situação afetiva familiar estaria ligada ao mecanismo de inibição do apego e à auto-suficiência (Guedes \& Miljkovitch, 2005), conforme se observa na Figura 2, sobre o apego com suas figuras parentais e amorosas: a segurança é fraca com os pais, mas é aumentada a cada experiência amorosa que vivencia.

Porém, enquanto mantém um baixo nível de ativação do apego, inibindo-o em relação aos pais, ele muda de estratégias entre seus parceiros, sem seguir uma única estratégia, demonstrando uma busca de um modelo mais eficaz que outro. Isso pode indicar uma diminuição de comportamentos arbitrários nas relações românticas em comparação às relações parentais - 0 que é esperado teoricamente, uma vez que os relacionamentos românticos tendem a ser menos pautados em um modelo de arbitrariedade como a que existe entre pais e filhos.

No entanto, os esforços desprendidos podem ter engendrado um estado psicológico ansioso, decorrente de percepções ligadas à atenção dispersa e à baixa concentração. Teoricamente, o indivíduo com estilo de apego ansioso tem dificuldade para se concentrar em atividades, uma vez que o mantém um estado de ansiedade voltada para suas figuras de apego, gerando dispersão da atenção (Main, 1990). Além disso, esse padrão pode ser transmitido para outras relações quando existe ameaça de ruptura (Bowlby, 1980, Guedes \& Miljkovitch, 2005).

Em síntese, podemos considerar que suas representações de apego em relação aos seus pais foram pautadas no sentimento de não ser amado de forma suficiente, no sentimento de rejeição deliberada, no modelo de relação instrumental, na ausência de partilha de experiências emocionais e no sentimento de amor condicional.

No âmbito das relações amorosas românticas, sua vivência parece repetir-se como a experiência afetiva vivida com os pais. Quando o laço era percebido como seguro, o temor pela perda parecia gerar a hiperativação do sistema de apego, como foi observado com o primeiro parceiro. Segundo Guedes e Miljkovitch (2005), tal hiperativação do sistema de apego pode ser caracterizada pelo sentimento freqüente de insatisfação na relação, necessidade constante de reafirmação do afeto por parte do outro, temor pelo abandono, mesmo que não existissem motivos, dramatização de situações e dificuldade em investir em outros domínios da relação. Vejamos um exemplo:

\footnotetext{
Chegou a um ponto em que parecia estar acostumado com essas situações de risco, como ceder a encontros com possibilidade de exposição pública, ou ao não uso de preservativos... Quando brigávamos, eu ligava e dizia que estava me sentindo mal, e realmente não sabia definir... só sabia que era um mal-estar intenso que apertava meu peito... Quando acabou, eu senti muita falta de compreensão e cada um queria ter razão...hoje sinto uma raiva intensa, aversão, mas também, ora sinto desejo sexual, ora raiva...
}

Assim, observou-se uma convergência entre a segurança do apego e a hiperativação do sistema de apego, na tentativa incoerente de manter uma relação, que ele percebia com riscos de ruptura. No entanto, no outro relacionamento, encontrou alguns elementos de segurança, que aliado a sua autocompreensão, possivelmente decorrente de seu processo psicoterápico, favoreceram novas representações sobre suas relações amorosas. Porém, ele optou por comportamentos de apego desativados, possivelmente com medo de frustrar-se na nova ligação. Um exemplo de sua fala caracteriza tal inibição do sistema de apego:

Ele é muito carinhoso, embora o volume de papo não seja grande... me chama pra viajar com ele, sair, mas eu não quero aprofundar essa relação... no momento quero só manter esse contato... tenho medo de me ligar muito a ele.

De acordo com entrevistas mais recentes, a atual relação mantém-se e as representações têm se mantido em torno da inibição do apego, mas tem sido ativada de forma adequada em alguns momentos de intenso engajamento amoroso. Crises de ciúme e alguns conflitos também são relatados. $\mathrm{O}$ atual parceiro amoroso responde às suas "expectativas" em termos de comportamentos representados como paternais. Entende-se que o movimento de Caio é de uma busca para uma estabilidade de sua relação amorosa atual, o que mediaria seu estado de humor e seu desempenho acadêmico e a qualidade mesma de sua vivência amorosa.

\section{Caso B}

Sua representação familiar indica a vivência em uma dinâmica de manifestações de apego inibidas: a vivência do apego com o pai era representada como frágil, marcada pelo 
sentimento de não se fazer objeto de atenção suficiente e pelo modo de relação instrumental. Eduardo considerava como "burocrática" ( sic) sua atenção, elemento que dá tonalidade de um estilo de desativação de suas memórias emocionais.

Com a mãe havia uma relação diferenciada. Pelo discurso de Eduardo, sua mãe compartilhava segredos e contornava o rigor disciplinar do marido. Porém, a relação dele com a mãe parecia desprovida de trocas de afeto, orientação e segurança emocional. As interlocuções íntimas relacionavam-se, em sua maioria das vezes, às demandas da mãe.

Ela costumava me contar algumas coisas que aconteciam na família e dava a impressão que aquilo era um segredo de estado, porque somente eu sabia e era capaz de compreender (...). Meu pai não poderia saber. (...) Minha mãe sempre foi mais maleável e tentava contornar algumas atitudes de meu pai (...) ela conversava comigo a sós, de maneira que ele não ficasse sabendo.

Assim, o nível de segurança na relação de apego com a mãe pode ser considerado como frágil, caracterizado pela inibição de estratégias de apego, como ausência de expressão dos sentimentos.

O perfil evitativo parece continuar nas relações amorosas. Eduardo restringe seu mundo ao trabalho, ao curso universitário e ao seu quarto, onde encontra seu veículo de comunicação que considera mais eficaz: o computador. Por ele, pode facilmente expressar seus pensamentos e crenças, assumindo um perfil extrovertido e otimista para com seus companheiros de internet. No entanto, sua autopercepção articulava-se a elementos autodepreciativos e repletas de sarcasmo e pessimismo. Definia-se como "ironia personificada" (sic) e, como tal, via-se constantemente em situações frustrantes após alguns momentos de satisfação (sobretudo no âmbito das relações amorosas).

Eduardo possuía um perfil internalizado do tipo de parceiro que considerava apropriado para ele. Caso alguns pontos desse "checklist" (sic) não fossem favoráveis, o possível parceiro era descartado ou, antes mesmo, evitado. No final de inúmeras seleções, via-se sozinho. Entende-se que suas exigências eram tão superiores que nunca encontrava o parceiro "adequado", apesar de sentir-se só e querer relacionar-se com alguém. Observam-se, mais uma vez, comportamentos característicos de pessoas com um estilo de apego evitativo.

Eduardo parecia funcionar como se estivesse atrás de provas para certificar-se que se "apegar" a alguém poderia gerar um sofrimento, possivelmente a partir das aprendizagens das experiências evitativas vividas anteriormente. Tais registros seriam reativados em situações semelhantes, indicando a necessidade de estratégias evitativas para enfrentá-las (Bowlby, 1973; Main, 1990).

Em suas duas primeiras ligações, manteve um baixo nível de segurança e de ativação do sistema de apego. Os aspectos relevantes dessas ligações, segundo sua representação, pareciam estar ligados ao fato de ele inibir seu comportamento de ligação amorosa em virtude das respostas inadaptadas dos parceiros, igualmente evitativas.

Na última relação, no entanto, utilizou estratégias outras de inibição do seu sistema de apego a fim de tentar manter a relação ao perceber uma base mais segura: evitar reconhecer suas próprias necessidades em detrimento da satisfação das necessidades do outro. Em síntese, em alguns momentos dessa última relação, houve um sentimento de segurança que o permitiu não frear seus comportamentos afetivo-amorosos. Entretanto, alguns comportamentos de distanciamento e/ou agressividade advindos do parceiro podem ter gerado um alerta da necessidade de aumentar as demandas de apego, o que possivelmente desembocou na evitação do parceiro e o desenlace amoroso.

Quando passou a integrar o significado desses "evitamentos" e a lançar mão de outras estratégias, sentiu-se confiante com a compreensão de sua "lógica amorosa" e se mostrou mais aberto para novas experiências. Seu estado depressivo alterou, sem medicamento, assim como seu desempenho acadêmico também se elevou, o que coincidiu com a vivência do apaixonamento. A última relação foi marcada pela cumplicidade: ambos tinham interesses comuns, concepções similares sobre diversas dimensões da vida e as famílias de ambos reconheciam a relação. Um quadro confortável e antes inimaginado. Porém, seu parceiro tinha propensões a respostas "grosseiras e hostis" (sic) quando se encontrava em situação de estresse, que Eduardo aceitava, mesmo que isso gerasse estresse emocional - o que bem ilustra como seu sistema de apego estava funcionando.

Após as desculpas do parceiro, o ciclo de apaixonamento recomeçava. Ao contrário do primeiro namoro, em que demandava mais atenção, nesse, a demanda dependia do estado de humor do outro. Ele parecia variar sua demanda de apego em função das respostas emitidas pelo parceiro. A partir desse ciclo, a relação permaneceu na fase do apaixonamento (Hazan \& Zeifman, 1994) até o momento em que começou a perceber outros sinais de evitação extrema do seu parceiro. Tais percepções, possivelmente, dispararam as antigas representações de perda vivenciadas e acionaram seus sintomas de depressão. No entanto, tinha maior clareza do fenômeno que se repetia: o da possibilidade da perda e de uma nova vivência de luto. De acordo com sua narrativa, ele afirma: "minha carência afetiva e estado depressivo eram insuportáveis. Me sinto péssimo. Chorei muito e estive em depressão desde então. Gosto muito dele ainda, mas tenho medo de reaproximações mais íntimas..."

Seu luto em relação ao último parceiro tinha completado o ciclo de elaboração, o que lhe permitiu investir em si e a buscar novas relações. A quantidade de sintomas da depressão foi diminuída, progressivamente, e Eduardo pôde explorar novos projetos no plano afetivo, profissional e familiar. Assim, compreende-se que seu estado depressivo esteve associado a suas vivências afetivo-amorosas e que seu percurso psicoterápico pareceu ter, por um lado, auxiliado a compreensão de padrões ante sua forma de estabelecer e manter suas relações, passando a vivenciar novas experiências.

\section{Conclusões}

Eduardo e Caio possuem pontos em comum quanto à vivência familiar e amorosa. Ambos possuíam uma vivência de segurança representada como "frágil" para com os pais e "moderada" para com os parceiros. De acordo com a narrativa de suas vivências amorosas, percebeu-se uma discreta elevação 
do nível de segurança (e por conseqüência da ativação do sistema de apego), demonstrando maior simetria na relação afetiva com os parceiros do que com os pais, o que é teoricamente esperado. Também verificou-se que a experiência de depressão foi moderada pela dinâmica das relações amorosas e as representações de apego com os pais podem ter influenciado no modelo de apego com os parceiros.

Com isso, nossas duas suspeitas iniciais são verificadas: tanto os modelos comportamentais de apego com os pais pareceram repetir-se com os parceiros amorosos, quanto os níveis de segurança e de ativação das relações amorosas pareceram mediar o nível da depressão dos clientes no sentido inverso quando o nível da segurança e de ativação do sistema de apego caiu, os da depressão aumentaram.

No entanto, este estudo revela alguns limites: primeiro que, em termos das relações de apego, a vivência insegura e evitativa pode gerar um efeito de distorção das representações e, portanto, das narrativas; segundo, embora a coleta de dados tenha ocorrido em um clima mais dialógico que investigativo, os dados podem ter sido enviezados pela saturação do inventário de depressão e pelo efeito da tendência em demonstrar uma auto-imagem positiva. Entende-se também que, apesar da coerência teórica sobre os comportamentos apresentados, não se pode afirmar que os participantes permaneceram nesse mesmo sistema comportamental. Todos esses parâmetros devem ser levados em conta ao analisar o conjunto explicativo proposto nesse estudo.

\section{Referências}

Ainsworth, M. D. S., Blehar, M. C., Waters, E., \& Wall, S. (1978). Patterns of attachment. Hillsdale: Erlbaum.

American Psychiatric Association. (2000). Diagnostic and statistical manual of mental disorders: DSM-IV-TR. Washington, DC: Autor.

Bowlby, J. (1969). Attachment and Loss - Attachment. Londres: Horgarth.

Bowlby, J. (1973). Attachment and Loss - Separation: anxiety and anger. Londres: Horgarth.

Bowlby, J. (1980). Attachment and Loss - Loss. Londres: Horgarth.

Bowlby, J. (1997). Formação e rompimentos de laços afetivos. São Paulo: Martins Fontes.

Guedes, D. D., \& Miljokovitch, R. (2005). Répresentations d'attachement et l'expérience de rupture de relation amoureuse. Manuscrito não-publicado, Universidade Paris X, Paris.

Hazan, C., \& Shaver, P. R. (1987). Romantic love conceptualized as an attachment process. Journal of Personality and Social Psychology, 52, 511-524.

Hazan, C., \& Zeifman, D. (1999). Pair bonds as attachment. In J. Cassidy \& P. Shaver (Orgs.), Handbook of attachment (pp. 336-354). Nova York: Guildford.

Hazan, C., Zeifman, D., \& Middleton, K. (1994). Adult romantic attachment, affect and sex. Comunicação apresentada em $7^{\text {th }}$ International Conference on Personal Relationships, Groningen, Holanda.

Main, M. (1990). Cross-cultural studies of attachment organization: recent studies, changing methodologies, and the concept of conditional strategies. Human Development, 33, 48-61.

Miljkovitch, R. (2005). Amour et ruptures: les traces laissés par l'enfance. Paris: Presses Universitaires de France.

Mohr, J. (1999). Same-sex romantic attachment. In J. Cassidy \& P. Shaver (Orgs.) Handbook of attachment (pp. 378-394). Nova York: Guildford.

Mohr, J. J., \& Fassinger, R. E. (2006). Sexual orientation identity and romantic relationship quality in same-sex couples. Personality and Social Psychology Bulletin, 32, 1085-1099.

Dilcio Dantas Guedes, mestre em Psicologia pela Universidade de Fortaleza e doutorando em Psicologia pela Universidade Paris X (França), é professor assistente na Universidade Estadual do Piauí. Endereço para correspondência: 103, rue Haxo; 75020 Paris-France. Tel./Fax: 00xx33-622846722. E-mail: dilcio@ gmail.com

Julieta Monteiro-Leitner, doutora em Psicologia Educacional pela Southern Illinois University (Carbondale, EUA), é professora assistente na Southeast Missouri State University. E-mail: jleitner@semo.edu 